$\xi=$ 离

\title{
Features and properties of viral and non-viral gene delivery systems towards effective gene therapy
}

\author{
Shettima Abubakar *, Muhammad M. Ibrahim, Musa Ibn Abbas \\ Department of Microbiology, University of Maiduguri, Nigeria \\ *Corresponding author E-mail: abshettima@unimaid.edu.ng shettima400@yahoo.com,
}

\begin{abstract}
Gene therapy has revolutionized the treatment of hereditary and genetic link disorders by consciously swapping, fixing, adding or deleting the genetic sequences responsible for the condition. The culprit cells are altered by inserting purposeful genes and incorporated into their genome for proper expression. Germ line therapy ensures the genotypic changes to be transferred to the next generation (offspring) while the somatic type adequately rest on corrective pedestals and as such not advantageous to the offspring. The earlier was constrained by technical difficulties as well as ethical consideration. The accomplishment of the therapeutic benefits of gene therapy requires a special ferry system "vectors". Vectors are designed to transfer the desired gene into its target cell without exposing it to some degrading enzymes, and must allow transcription to successfully take place. A model vector must not be immunogenic, it must not trigger high immune response detrimental to the patient and a specific tropism must be a pre-requisite. The choice of a vector should be based on safety, cost and availability as well as the accessibility of possible options. Mainly for viral carriers, host immune response trigger are the main concern. Viral vectors most frequently used in gene therapy include adenoviruses, retroviruses, poxviruses, adeno-associated viruses and herpes simplex viruses.
\end{abstract}

Keywords: Gene Therapy; Germ Line; Somatic; Viral Vectors; Non-Viral Vectors; Ethics.

\section{Introduction}

Gene therapy is an important means in the treatment of genetic disorders and other gene implicated or associated conditions. There are several scholarly definitions of gene therapy. An elucidated definition by the European Medicines Agency (EMA) states that a gene therapy is a biological medicinal product that accomplishes two specific characteristics. i. A recombinant nucleic acid (DNA/RNA) used in or administered to human beings purposely to regulate, repair, replace, add or delete a genetic sequence. ii. The therapeutic, prophylactic, diagnostics effect correlates directly to the recombinant nucleic acid sequence it contains, to the product of genetic expression of this sequence. And the US Food and Drug Administration (FDA) defines gene therapy as a product that mediate their effects through transcription and or translation of transferred genetic material and or by integrating into the host genome and administered as nucleic acids, viruses, or genetically altered microorganism. The products may be used to transform cells in vivo/ex vivo before administration to the beneficiary (Wirth et al., 2013). Simply, a gene therapy implies any technique deliberately intended to treat or ease a disease by genetically engineering the cells of a patient. Genes, gene segment or oligonucleotides may be modified to achieve the therapy (Amer, 2014). A new approach that tends to alter the expression of some genes to treat, cure or ultimately prevent diseases (Katare and Aeri, 2010). The first breakthrough in gene therapy reported in 1990, in a young girl suffering from $\mathrm{X}$ chromosomal link condition called severe combined immunodeficiency (SCID), and was treated with a retroviral vector containing cDNA copy of the gene coding for adenosine deaminase enzyme (ADA) at the National Institutes of Health (NIH) in Bethesda, Maryland, USA. The buildup of deoxy- adenosine in circulation is toxic, poisonous and lethal to some cells, including T lymphocytes. ADA principally converts deoxyadenosine to its metabolites (Lemoine and Cooper, 1996). The success has shown a genuine continuing or everlasting cure for hereditary diseases is attainable (Lundstrom, 2003).

The importance of gene therapy cannot be overemphasized. Gene therapy carries the enthusiasm of a solution for a wide range of disease and the possibility to bring to an end or to prevent inherited disease like cystic fibrosis and haemophilia, and its use as the likely cure for heart disease, AIDS, and cancer (Katare and Aeri, 2010). The property of selectively targeting defective gene or neoplastic cell has given gene therapy a promising phenomenon for treatment especially in metastatic cancer patients who are often incurable, or a gene implicated diseases (Mali, 2013). Check (2002) reported the development of leukemia like-condition by a patient who received a successful genetic treatment for SCID from a French trial. Scientist believed that it was connected to the treatment.

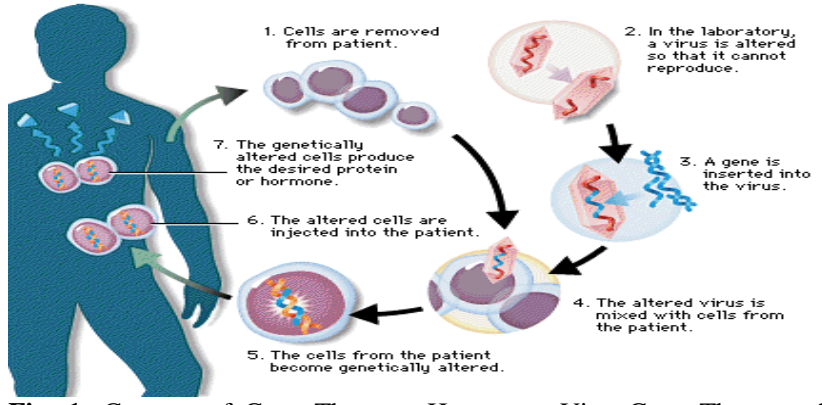

Fig. 1: Concept of Gene Therapy: Human ex Vivo Gene Therapy, the Principle as Used in the First Clinical Trial in the 1990s, in the US (Patil, Et Al., 2012). 


\section{Gene therapy types}

There are two types of gene therapy- germ line gene therapy and somatic gene therapy. Germ line cells are specialized and dedicated cells producing gametes for the continuity of species (Dunlop et al., 2014). These cells are altered by inserting purposeful genes and incorporated into their genome. As a result, next generation would show the genotypic changes due to the therapy. This approach, in theory, should successfully treat genetic diseases and hereditary disorders; but it is questionable to try clinically in humans as technical difficulties and ethics hindered it realisation (Misra, 2013). The United Kingdom has approved mitochondrial DNA replacement, and the outcome would be passed to the subsequent generation, a sort of germline gene therapy (Jones, 2015). This is indeed a remarkable development. While insertion of genes into specific somatic cells is termed somatic gene therapy. Hence, any corrective changes will not pass to the next generation or the offspring (Wirth et al., 2013).

\subsection{Vectors and delivery systems}

To achieve effective therapeutic benefits through gene therapy, the transfer of the gene to the target genome is the primary and initial step. Insertion of histone-free DNA referred to as naked DNA through injection is considered to be the easiest method of gene delivery coupled with its characteristics of encoding beneficial protein molecule. The reduced efficiency of this method, however, led to the development of a special method to improve gene delivery and hence the use of vectors. A vector simply refers to a transfer system that transmits a particular therapeutic gene into its target cell without exposing it to degrading enzymes and allowing transcription to occur. Properties attributed to vectors include the ability to transfer specific genes and nucleic acid into target cells, protection from the destructive enzyme and successful transcription within the cell. The ideal vehicle must not induce a high immune response, it should equally have specific tropism apart from being safe, chief and easy to produce and available commercially (Somia and Verma 2000; Gardlík et al., 2005; Bolhassani and Rafati, 2011). Vectors used in gene therapy are categorized into viral vectors and non-viral vectors (Ibraheem, et al., 2014). Vectors are ferry systems.

\subsubsection{Adenovirus vector (AD)}

Discovered in 1953 from human adenoid tissue, human adenovirus are classified as non-enveloped DNA viruses with linear dsDNA of about $35 \mathrm{~kb}$. About 49 unique serotypes were well-known, further classified based genome homology and organization, oncogenicity and haemaggulutination properties into A to E subgroups and the most thoroughly characterised are type 2 and type 5 belonging to the $\mathrm{C}$ group. The viral capsid comprised of three major and several minor proteins. The abundant structural component called hexon made the bulk of the protein shell which essentially acts as a coating protein. The penton base and the fiber control virion cell interaction that establishes the viral tropism (Enders et al., 1956; Glasgow et al., 2006; Walther and Stein, 2000). (Fig 3: Ad structure).

Ad is a common pathogen, and in the most patient it causes minor, self-limiting illness that resolves without treatment and the most commonly used vector delivery systems in human gene therapy clinical trials. Mostly, the essential early region 1 (E1) in Ad vectors are deleted; this renders them not able to replicate in several cell line (Ginn et al., 2013; Saha et al., 2014). Ad enters a cell through attachment to a receptor molecule expressed at the cell surface, after the interaction with molecules resulting in virion internalization. The high binding affinity of the virion primarily occurs through direct binding of the fiber knob domain to its similar primary cellular receptor, for most serotypes they are coxsackie and adenovirus receptor (CAR) including the most employed in gene therapy Ad2 and Ad5 respectively (Glasgow et al., 2006).

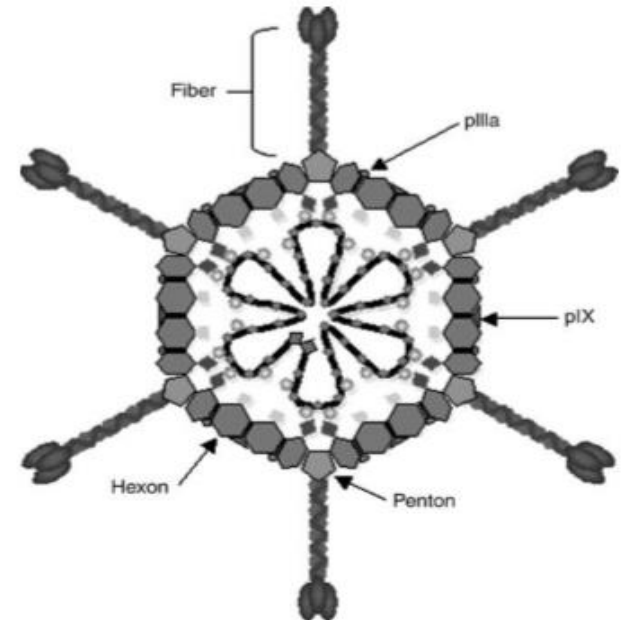

Fig. 2: Wild Type Adenovirus Capsid, Showing Hexan, Penton, Pix, Piiia, and Fiber Structures, It Contains About 36 Kilobase Dsdna Genome Inside the Capsid (Glasgow Et Al., 2006).

In the cell host, the viral particle is equipped with proteins that facilitate endosomal lysis and evasion letting the genome enters the nucleus. The E1 genes undergo transcription and act as a master transcriptional regulator that primarily initiates the process of viral gene expression to replication, E2, and E4 genes are prerequisite for viral genome replication in addition to the E1 genes. At the end of the life cycle, the viral structural proteins are transcribed leading for encapsidation of a newly replicated genomes. The E3 genes normally not required for the viral life cycle, but responsible for immune surveillance of the wild-type infection in an infected host. Deletion of the E3 regions creates additional space for larger foreign DNA inserts (Kay et al., 2001).

\subsubsection{Adeno-associated viruses (AAV)}

Originally described as a 'defective virus' discovered as a contaminant in laboratory stocks of Av. AAV is a single-stranded DNA virus from the Parvovirinae subfamily of about $4.7 \mathrm{~kb}$ genome. The ssDNA then converts to form a double stranded template the following infection by exploiting more than $95 \%$ coding capacity of the genome. AAV undergoes a distinctive viral life cycle as infected cell might either produce a lytic infection or persistence of the viral DNA molecule following integration into host chromosomal DNA in the infected cell. After infection, gene expression result in the production of replication (Rep) and structural (Cap) proteins. As a prerequisite for replication, AAV needs the replication properties from co-infecting viruses such as Ad or herpesvirus, which in natures serves a helper viruses for AAV. Without the helper virus or helper replication factors, wild type AAV integrates into the host cell genome as a dsDNA to persist in a latent stage. AAV can be activated from the latent state to an infectious virus through infection with a helper virus (Mohanan and Samulski, 2000; Jooss and Chirmule, 2003).

There are six serotypes identified, and the sequence serotypes of AAV showed a significantly different amino acid sequence. Serotypes 1 and 6 have a 99\% homology in their capsid proteins (Rabinowitz and Samulski, 2000). AAV serotype 2 is the widely used vector of AAV-based followed by other serotypes such as AAV1, AAV3, AAV4, AAV4, and AAV6. AAV2 recombinant vectors produced through the insertion of a therapeutic gene between two inverted terminals repeats (ITRs) substituting all coding genes except ITRs. The resultant recombinant AAV plasmid is cotransfected into HEK 293 cells using a helper plasmid with Rep and Cap genes and Ad E2A, E4 and VA genes required for expression of the AAV genes, nonetheless without the AAV ITRs (Gardlík et al., 2005).

The characteristic advantage of AAV is its defective nature and the confirmed continuing therapeutic gene expression. It is also described as highly stable, safe and efficient, resistance to heat inactivation with a property of extensive host range and extended 
tissue tropism and above all its nonpathogenic and does not induce a significant cell-mediated inflammatory response. AAV are originally from human viruses thus are more practicable for genetic treatment. However, AAV has a small packaging capacity. The risk of insertional mutagenesis because of integrating carrier vectors and are challenging to produce higher titers for clinical trials (Mohanan and Samulski, 2000; Kimura et al., 2001; Jooss and Chirmule, 2003; Wang et al., 2004; Gardlík et al., 2005).

\subsubsection{Retroviruses}

The first retroviruses were discovered and identified in a chicken as a cell-free oncogenic factor. Several of the oncogenic retroviruses have been shown to occur as defective viruses that have replaced a fragment of their usual gene complement with an oncogene. Retroviruses are widespread throughout the animal kingdom (Anson, 2004). Retroviruses are ssRNA viruses, with a diameter of 80-130nm and 8-11 kb spherical genome size. It's an enveloped virus particle containing two copies of RNA genome rounded by a cone-shaped core (Verma and Weitzman, 2005), and having the property of reverse transcribing their viral RNA genome into a dsDNA then firmly inserted into host DNA (Walther and Stein, 2000). The viral RNA comprises three essential genes surrounded by long terminal repeat (LTR). The core protein capsid is encrypted by the gag gene, the matrix, and the nucleocapsid is produced by the proteolytic cleavage of the gag precursor protein. Viral enzymes, protease, reverse transcriptase, and integrase derived from gag-pol precursor encrypted by the pol genes and the envelope glycoprotein that facilitate viral entry encoded by the pol gene (Verma and Weitzman, 2005).

In a wide-ranging species, a replication competent retrovirus can cause malignant disease and other series of pathologic conditions such as AIDS. Also, several retroviruses lead to life-long infection and seem to be moderate, if not totally benign, in their usual host species. However, spumaviruses or foamy viruses (class of retroviruses) appear not to be related to any pathologic state and even the simian immune deficiency virus equivalent of HIV-1, the aetiology of AIDS, is not pathogenic in all of its hosts. But exhibit a distinct tropism (Anson, 2004).

By constructing a transfer vector, the three main structural (gag, pol, env) genes are deleted and substituted by a therapeutic gene. These deletions render the virus replication defective. As a result, vectors can produce viral properties only if transfected to PCL. This integration property of retrovirus is a useful tool in gene therapy (Gardlik et al., 2005).

Advantages of retroviral vectors are determined by their unique feature of stable integration into the host genome, ease of sufficient viral titres production for effective gene transfer, infectivity of the recombinant viral particle for a range of target cell types and carrying capacity of $<8 \mathrm{~kb}$ (Walther and Stein, 2000). Disadvantages of retroviral vectors are the instability attributed to it, insertional mutagenesis as a result of random viral integration and the need for cell division for integration of MuLV derived retroviral vectors. Retroviral vectors still have unsatisfactory clinical applications (Walther and Stein, 2000).

\subsubsection{Lentiviruses}

Lentiviral vectors are the most widely studied retroviral vectors for genetic treatment; this is because of the AIDS epidemic (Anson, 2004). Lentiviruses are a subfamily of retroviruses; it encodes for three to six more viral genes (tat, rev, vif, vpr, nef, and vpu) than the three main structural protein of retroviruses (gag, pol and env) contributing to viral replication and infection persistence. Tat and rev accessory protein are resident in all lentiviruses and facilitate transactivation of viral gene transcription and nuclear export of unspliced viral RNA (Verma and Weitzman, 2005). Lentiviruses (HIV) exhibit a special feature in which they can infect cells after mitosis as it encrypts viral matrix protein with a nuclear localization signal that mediates active transport of the prior viral integration using nucleopore. This property makes possible the integration into host chromosome without mitosis (Kaplitt et al., 1998).

The retroviral vector design provided an excellent model for making lentiviral vectors. The HIV -1 based lentiviral vectors only contain the essential cis-acting sequences, including the LTRs and the packaging signal but are lacking all the viral genes. The RNA vector also contains the rev responsive element (RRE). The rev gene is provided in trans as to make the competent nuclear export of the complete viral RNA genes by attaching to the RRE. Endogenous LTR was primarily employed to drive vector RNA expression through the transactivation by the tat gene. Further generation vectors are hybrid which enhances vector production and without tat expression because of the CMV/LTR hybrid promoter (Verma and Weitzman, 2005). Current lentiviruses are reasonable safe as the replication of the vectors is well inhibited and the recombination is highly decreased because they contain no additional genes.

\subsubsection{Herpes simplex viruses (HSV)}

HSV is one of the largest human viruses known. HSV is an enveloped dsDNA virus with about $150 \mathrm{~kb}$ in size. A member of herpesviridae family is considered as natural human pathogen and pathogen of oral vesicular lesions, replicating in epithelial cells and non-mitotic cells it stays latent. Initial HSV 1 and HSV 2 infections are symptomless and resolve without treatment, but the complication is seen in neonates fulminating disease (Gardlík et al., 2005; Sheng et al., 2015). HSV vectors based on HSV 1 and can be obtained in two ways: first through inserting the therapeutic protein into a plasmid with the HSV origin of replication and a packaging signal and then by transfecting the cells and infecting with helper HSV. Second Introduction of the gene directly into HSV genome, achieved by cloning the gene into plasmid bound to definite HSV sequences. The plasmid is then co-transfected into cells with HSV (Latchman, 2001; Gardlík et al., 2005).

\subsubsection{Viral gene delivery}

Viruses are intracellular parasites that direct the cellular apparatus of their host cell to express their genetic material necessary for replication. Viruses contain either RNA or DNA as their genetic material and the nucleic acid could be single stranded or double stranded. Expression of a viral gene inside the host cell and appearance of viral regulatory products is the start of the infection process of viruses (infection cycle) followed by expression and assembly new viral particles (replication cycle). A modified gene (therapeutic gene) replaces the viral genome while maintaining its structural ability to infect cell and replicate. (Kay et al., 2001; Berk et al., 2000). The resulting nonpathogenic virus containing the corrective gene for treatment is referred to as viral vector (Ibraheem et al., 2014), figure 2 shows the strategy to modify virus into a vector. 

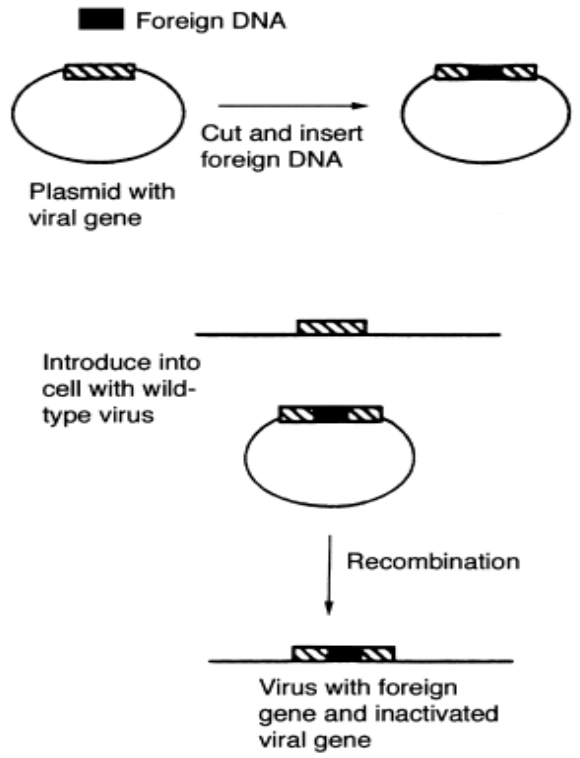

Fig. 3: Recombination of Foreign of DNA into HSV 1 Genome (Latchman, 2001)

\begin{tabular}{|c|c|c|}
\hline Viral vector & Prons & Cons \\
\hline Av vectors & $\begin{array}{l}\text { Production of high virus titers about } 10^{10}-10^{12} \mathrm{pfu} / \mathrm{ml}, \mathrm{In}- \\
\text { creased level gene expression, large insert capacity }(7-8 \mathrm{~kb}) \text {, } \\
\text { infect dividing and non-dividing cells }\end{array}$ & $\begin{array}{l}\text { Immune response to viral proteins, lack of integra- } \\
\text { tion into host cell genome, transient gene expres- } \\
\text { sion }\end{array}$ \\
\hline AAV vectors & $\begin{array}{l}\text { Infect dividing and non-dividing cells, broad cell tropism, } \\
\text { potential of targeted integration, low immunogenicity and } \\
\text { nonpathogenic }\end{array}$ & $\begin{array}{l}\text { Limited capacity for transgenes }(4 \mathrm{~kb}) \text {, difficult } \\
\text { generation of high virus titers, requirement of ade- } \\
\text { novirus or herpesvirus for AAV replication }\end{array}$ \\
\hline Retroviruses vectors & $\begin{array}{l}\text { Insert capacity for transgene }<7-8 \mathrm{~kb} \text {, stable integration into } \\
\text { host DNA, recombinant virus titers of } 10^{6}-10^{7} \mathrm{pfu} / \mathrm{ml} \text {, broad } \\
\text { cell tropism of infectivity, relatively easy manipulation of viral } \\
\text { genome for vector engineering }\end{array}$ & $\begin{array}{l}\text { Difficult targeting of viral infection, no infection of } \\
\text { non-dividing cells, random integration into host } \\
\text { genome, instability of vectors }\end{array}$ \\
\hline Lentiviruses vectors & $\begin{array}{l}\text { Infect dividing and non-dividing cells stable gene expression, } \\
\text { insert capacity of } 10 \mathrm{~kb}\end{array}$ & $\begin{array}{l}\text { Potential insertional mutagenesis, presence of } \\
\text { regulatory (tat, rev) and of accessory protein } \\
\text { sequences in the packaging constructs }\end{array}$ \\
\hline $\begin{array}{l}\text { HSV vectors } \\
\text { Av = Adenovirus; } A\end{array}$ & $\begin{array}{l}\text { Infects a wide variety of cell types, high insertion capacity (up } \\
\text { to } 50 \mathrm{~kb} \text { ), and natural tropism to neuronal cells stable viral } \\
\text { particles allow generation of high virus titers }\left(10^{12} \mathrm{pfu} / \mathrm{ml}\right) \text {. } \\
\text { sociated virus; pfu = Plaque forming unit }\end{array}$ & $\begin{array}{l}\text { toxicities, fear of recombination, no viral integra- } \\
\text { tion into host DNA }\end{array}$ \\
\hline
\end{tabular}

(Walther and Stein, 2000; Ibraheem et al., 2014).

Table 2: Viral Vector Clinical Applications

\begin{tabular}{|c|c|}
\hline Viral vector & Clinical Applications and Trials \\
\hline AV vectors & $\begin{array}{l}\text { - Used in treatment of cystic fibrosis, the CFTR gene transfected into nasal epithelium by either Ad2/Ad5 vectors. The re- } \\
\text { sult was transient reconstitution of the chloride transport at the site of vector insert in patients. } \\
\text { Ornithine transcarbamylase deficiency OTC leading to hyperammonaemia was treated by Batshaw and co employing Ad } \\
\text { vectors for the transduction of the OTC gene into the liver of patients with the disease to restore enzyme activity to near } \\
\text { normal. } \\
\text { Ad vectors used in therapeutic formation of new blood vessels (angiogenesis). Genes for vascular endothelial growth fac- } \\
\text { tor in Ad vectors performed in vivo by intra coronary use for treatment of ischaemic myocardium and into the lower limb } \\
\text { to treat ischaemic myoblast }\end{array}$ \\
\hline AAV vectors & $\begin{array}{l}\text { - Used in CFTR gene therapy for cystic fibrosis and haemophilia B } \\
\text { - Successful in animal model human diseases such as } \beta \text {-thalassaemia, sickle cell anaemia, chronic granulomatous disease } \\
\text { and Parkinson's disease etc }\end{array}$ \\
\hline HSV vectors & $\begin{array}{l}\text { - Used in Parkinson's disease animal model and animal model of cancer } \\
\text { - } \quad \text { HSV } 1 \text { vector gene therapy of human glioblastoma (clinical trial) } \\
\text { - Certain brain disease and spinal nerve injury } \\
\text { Adeno-associated virus; HSV = Herpes simplex virus }\end{array}$ \\
\hline
\end{tabular}

(Walther and Stein, 2000; Kay et al., 2001; Gardlik et al., 2005; Lizuka et al., 2015).

The main characteristic features that made viruses a desirable vector in gene therapy is the natural ability of effectively transferring their genes into the host cell and high carrying capacity of foreign genes by specific viruses (Walther and Stein, 2000). The nature of disease presentation is important in considering which viral vector to select. The required duration of therapies ranges from long-term gene transfer to short-term or regulated gene delivery and either systemic or localized. The most frequently employed gene delivery in more than $70 \%$ of all clinical trial includes adenoviruses (Ad), retroviruses, and poxviruses, adeno-associated viruses (AAV) and Herpes simplex viruses (HSV). These vectors possess properties that made them an ideal candidate for several therapeutic functions (Stone, 2010).

There are safety issues arising from the use of viral vectors with the few exceptions. The wild type class of several viruses employed to make a viral vector are pathogens with intrinsic safety concerns. Notwithstanding the efforts to reduce the potential risk of individual viruses through deletion, insertion, or direct engineering of the genome, without affecting its role as a beneficial vector. To make a virus safe is not always successful, therefore, it is pertinent to note the potential hazards of individual vector prior to application and to measure the advantages and disadvantages of 
available options. Initiation of host immune response is the main concern after viral gene delivery. This response can either be a delay in the success of the therapy and/or the overall health of the individual (Raper et al., 2003; Stone, 2010).

\subsubsection{Non-viral gene delivery}

Non-viral gene delivery systems represent the expression of a simple and above all safety of administration with low host immunogenicity, although characterized by its less efficiency at putting and sustaining gene expression of foreign nucleic acid (Thomas and Klibanov, 2003). The non-viral vectors contain naked DNA; they are physical and chemical based, administered through direct injection either plasmid DNA, naked DNA, chemical or physical.

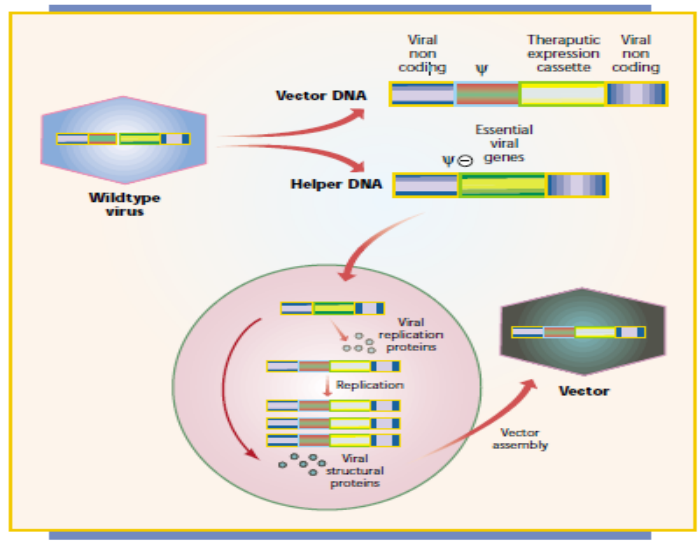

Fig. 4: Modification of Virus into a Vector (Kay Et Al., 2001).

Consequently, Park et al., (2006) reported three categories to achieved non-viral gene delivery that consist of (a) naked DNA (b) lipid based and (c) polymer based delivery Most clinical trials in cardiovascular treatment employ the use of non-viral systems of therapeutic genetic transfer. The demonstrated decrease in pathogenicity cost effectiveness and simplicity of production and safety made non-viral gene delivery significantly advantageous over viral carriers. The main advantage of non-viral methods of delivery over viral methods of delivery is its biological safety. But the application of the non-viral methods reported to be neglected in the past as a result of poor effectiveness in delivery reducing expression of the modified genes (Glover et al., 2005; Ramamoorth and Narvekar, 2015). Figure 5 depicts representation non-viral delivery methods in a chart.

The hydrophilic nature and the negatively charged phosphate groups of the naked DNA molecule limit its effectiveness to enter a cell and they are also easily broken by enzymes. The changes are to figure out ways to overcome these barriers (Cevher et al., 2012).

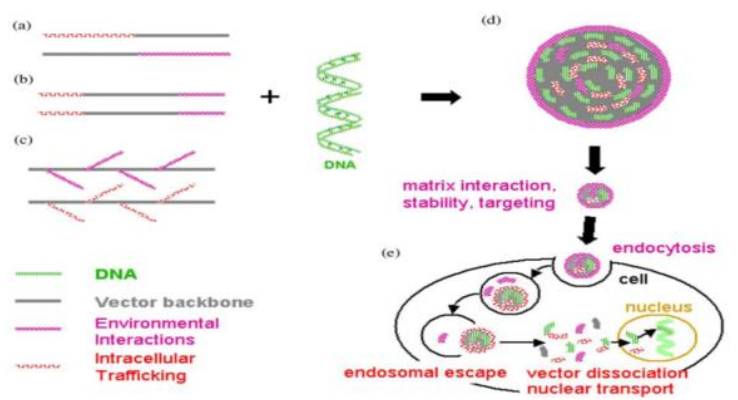

Fig. 2: Presentation of Non-Viral Vector Design (Ramamoorth and Narvekar, 2015).

\subsubsection{Physical methods}

i) Gene gun

In this method, DNA coated with gold particle and laden into a device that makes a force resulting in penetration of DNA/gold into desired cells. However if the integration of the DNA occurred in the wrong region of the cell, the unwanted gene might be expressed as seen in the clinical trials of X-SCID patients. The methodology has been successfully employed to insert DNA in vivo into several organs, including liver, skin, pancreas muscle, spleen and tumour. Skin vaccination against melanoma using tumour associated antigen (TAA) human gp100 and reporter gene assays have been conducted using the gene gun delivery methods (Bolhassani and Rifati, 2011; Patil, et al., 2012).

ii) Electroporation

In this method, a specific strength of short electric pulse makes a hole in a cell membrane through which a foreign can be inserted into a cell. A capacitor releases the electrodes across, from a specially generated electroporation chamber that makes the pulse needed for an adequate transfer of the nucleic acid by electroporation. The pulse may either be a high voltage rectangular wave or a low voltage pulse for short and long duration $(1.5 \mathrm{kV}$ or $350 \mathrm{kV}$ ) respectively. Successful used of electroporation was reported in transfecting muscles, brain, skin, liver and tumours (Bolhassani and Rifati, 2011; Katare and Aeri, 2010).

iii) Microinjection

In 1980, Jon Gordon demonstrated that exogenous DNA could be inserted into a germline easily through physical injection of a solution of clones DNA into zygote pronuclear (Smith, 2004). Microinjection is glass capillaries for injecting DNA into the nucleus of target cell directly (Katare and Aeri, 2010).

iv) Ultrasound

DNA delivered into cells using ultrasonic frequencies. The process of acoustic cavitation is believed to disrupt the cell membrane and permit DNA into the host cells (Patil et al., 2012).

v) Hydrodynamic

Gene delivery is achieved through hydrodynamic pressure mediated by the injection of the large volume of DNA solution and blood pressure inside the veins. As a result, the capillary endothelium permeability increases and form pores in the plasma membrane surrounding parenchyma cells, DNA can get into cells through the pores created (Cevher et al., 2012).

\subsubsection{Chemical methods}

i) Liposomes/cationic lipids Integration of foreign DNA into phospholipids vesicle by sonification of solution of lipids and the DNA in an ether. Liposomes are formed from the lipid that enclose the DNA within it and are divided into cationic, anionic and neutral based on their charges (Katare and Aeri, 2010; Cevher et al., 2012).

ii) Dendrimer

A spherical shapes highly branched macromolecule. The surface particle is possible to be modified to construct a cationic dendrimer. In the presence of nucleic acid (DNA/RNA), complementarity leads to an association of the nucleic acid with cationic dendrimer; and on reaching its target, the complex is then endocytosed (+ cation and - DNA) (Patil et al., 2012).

iii) Synthetic proteins

Several number of synthetic carries of DNA have been made. An example is the complex of spermine that have a positive charge that forms lipospermine when attached to lipids. The interaction of the positive and negative charges form a casing around the DNA. The lipospermine then interacts to form another casing with an outer surface positively charges as a result of spermine (Katare and Aeri, 2010). 


\section{Liposome for Drug Delivery}

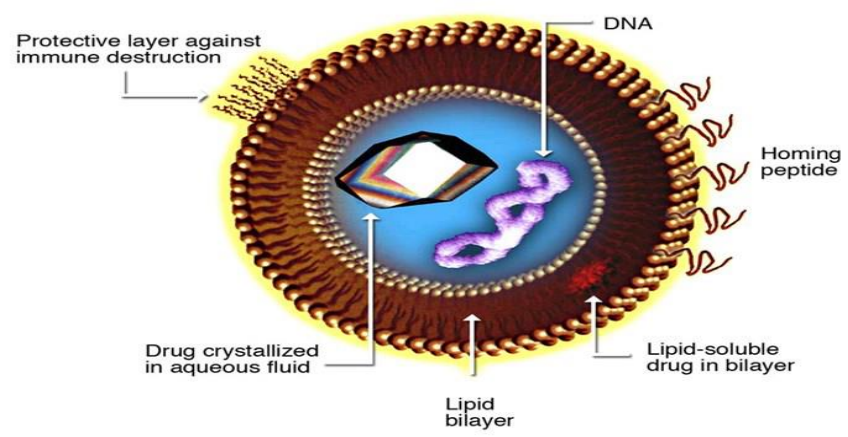

Fig. 3: Liposome Used or Drug Delivery (Patil Et Al., 2012).

Table 3: Non-Viral Vectors Advantages and Disadvantages

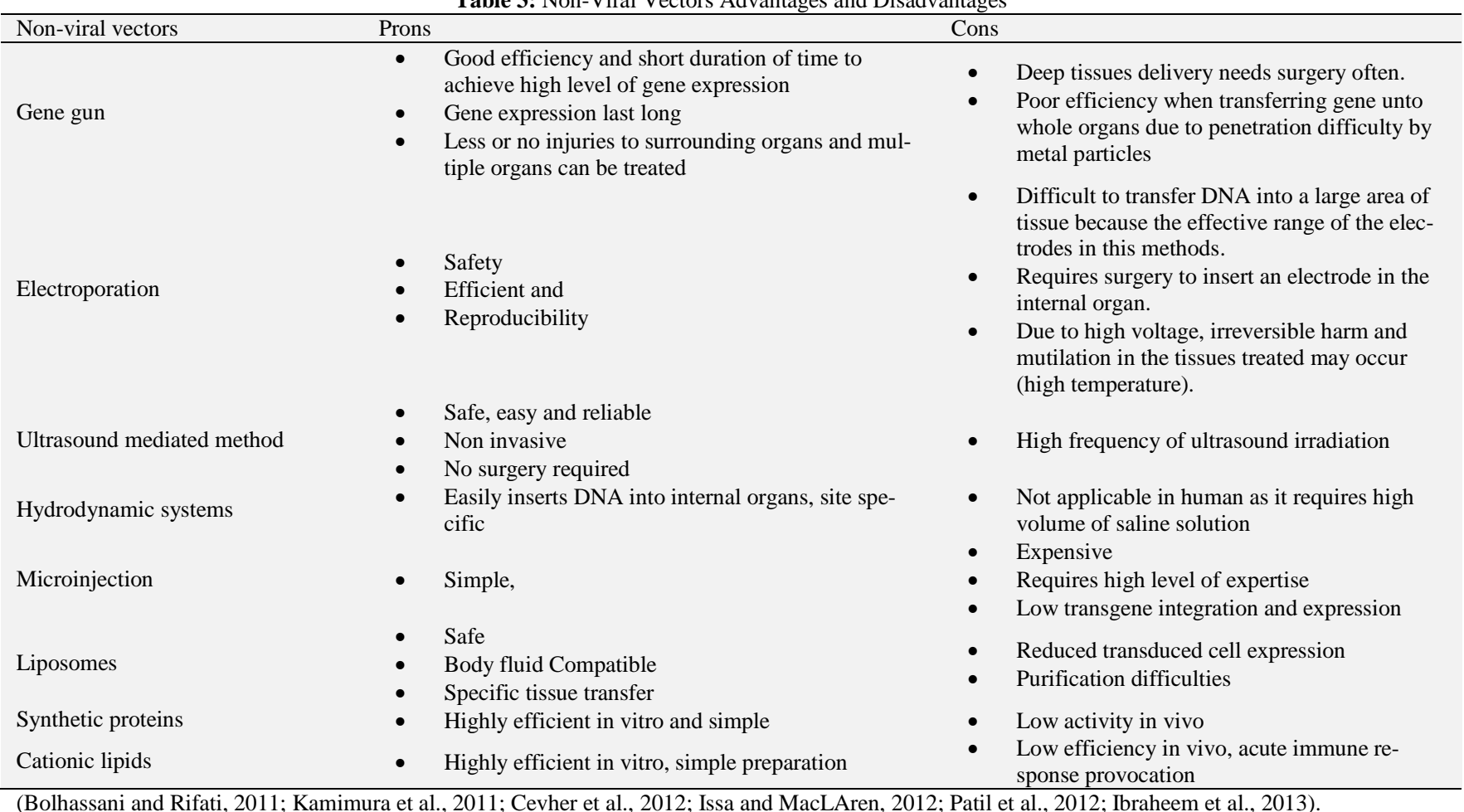

\section{Ethical consideration}

In the UK, all research for ethical approval of a gene therapy must go through the Gene Therapy Advisory Committee (GTAC) according to regulation 14(5) of the Medicines for Human use (Clinical Trials) Regulations 2004 appointed by the Health Research Authority (HRA, 2015).

There have been genuine ethical concerns because of the mode of action of the products of gene therapy in the treatment of human disease. Both critics and advocates agree that risk of gene therapy must not be considerably greater than the intended benefits. There is also concerns about whether it is right or wrong ethically especially the germline therapy (Misra, 2013; Writh et al., 2013).

Misra (2013) reported some of the ethical considerations for gene therapy viz:

- Deciding what is normal and disability

- Deciding if disabilities are diseases and if they should be cured

- Deciding if somatic gene therapy is more or less ethical than germ line gene therapy.

- Etc

\section{Conclusion}

In conclusion, gene therapy remains an important protocol for a broad range of disease and the possibility to prevent inherited disease like Duchenne Muscular Dystrophy, cystic fibrosis and in the development of a cure for conditions like AIDS and cancer. The feature of selectively targeting defective gene or abnormal cells has given genetic treatment an advantage in controlling and even eradication gene implicated diseases, most of the time incurable.

The used of viral vectors to deliver a therapeutic gene to a target should tightly be regulated, and ethical approval should be sorted for the treatment of any kind. Pros and cons measured appropriately. 


\section{References}

[1] Wirth, T., Parker, N. and Ylä-Herttuala, S. (2013) History of gene therapy. Gene [online], 525:2, 162-169 https://doi.org/10.1016/i.gene.2013.03.137.

[2] Amer, M.H. (2014) Gene therapy for cancer: present status and future perspective. Molecular and Cellular Therapies [online], 2(1), pp. 27. https://doi.org/10.1186/2052-8426-2-27.

[3] Katare, D.P. and Aeri, V. (2010) Progress in gene therapy: A Review. IJTPR [online], 1pp. 33-41.

[4] Dunlop, M.G., 1997. Gene Therapy. Edited by NR Lemoine and DN Cooper. Bios Scientific Publishers, 1996

[5] Lundstrom, K. (2003) Latest development in viral vectors for gene therapy. Trends in biotechnology [online], 21(3), pp. 117-122. https://doi.org/10.1016/S0167-7799(02)00042-2.

[6] Mali, S. (2013) Delivery systems for gene therapy. Indian journal of human genetics [online], 19(1), pp. 3 . https://doi.org/10.4103/0971-6866.112870.

[7] Check, E. (2002) Gene therapy: a tragic setback. Nature [online], 420(6912), pp. 116-118. https://doi.org/10.1038/420116a.

[8] Patil, P., Chaudharie, P., Sahu, M. and Duragkar, J. (2012) Review article on gene therapy. Int J Genetics [online], 4(1), pp. 74-79. https://doi.org/10.9735/0975-2862.4.1.74-79.

[9] Dunlop, C.E., Telfer, E.E. and Anderson, R.A. (2014) ovarian germline stem cells. Stem Cell Res Ther [online], 5(98), pp. 10.1186. https://doi.org/10.1186/scrt487.

[10] Misra, S. (2013) Human gene therapy: a brief overview of the genetic revolution. J Assoc Physicians India [online], 61(2), pp. 127133.

[11] Jones, D.A. (2015) the other woman: Evaluating the language of 'three parent'embryos. Clinical Ethics [online], 10(4), pp. 97-106. https://doi.org/10.1177/1477750915599721.

[12] Somia, N. and Verma, I.M. (2000) Gene therapy: trials and tribulations. Nature Reviews Genetics [online], 1(2), pp. 91-99. https://doi.org/10.1038/35038533.

[13] Gardlik, R., Palffy, R., Hodosy, J., Lukacs, J., Turna, J. and Celec, P. (2005) Vectors and delivery systems in gene therapy. Medical science monitor: international medical journal of experimental and clinical research [online], 11(4), pp. RA110-21.

[14] Bolhassani, A. and Rafati, S. (2011) Non-Viral Delivery Systems in Gene Therapy and Vaccine Development. [online] INTECH Open Access Publisher.

[15] Ibraheem, D., Elaissari, A. and Fessi, H. (2014) Gene therapy and DNA delivery systems. International journal of pharmaceutics [online], 459(1), pp. 70-83. https://doi.org/10.1016/j.ijpharm.2013.11.041.

[16] Kay, M.A., Glorioso, J.C. and Naldini, L. (2001) Viral vectors for gene therapy: the art of turning infectious agents into vehicles of therapeutics. Nature medicine [online], 7(1), pp. 33-40. https://doi.org/10.1038/83324.

[17] Berk, A., Zipursky, S. and Lodish, H. (2000) Molecular Cell Biology 4th edition. [Online].

[18] Walther, W. and Stein, U. (2000) Viral vectors for gene transfer. $\begin{array}{llll}\text { Drugs } & \text { [online], 60(2), pp. } & \text { 249-271. }\end{array}$ https://doi.org/10.2165/00003495-200060020-00002.

[19] Stone, D. (2010) Novel viral vector systems for gene therapy. Vi$\begin{array}{llll}\text { ruses } & \text { [online], } & 2(4), & \text { pp. }\end{array}$ https://doi.org/10.3390/v2041002.

[20] Raper, S.E., Chirmule, N., Lee, F.S., Wivel, N.A., Bagg, A., Gao, G., Wilson, J.M. and Batshaw, M.L. (2003) Fatal systemic inflammatory response syndrome in a ornithine transcarbamylase deficient patient following adenoviral gene transfer. Molecular genetics and metabolism [online], 80(1), pp. 148-158 https://doi.org/10.1016/j.ymgme.2003.08.016.

[21] ENDERS, J.F., BELL, J.A., DINGLE, J.H., FRANCIS, T.,Jr, HILLEMAN, M.R., HUEBNER, R.J. and PAYNE, A.M. (1956) Adenoviruses: group name proposed for new respiratory-tract viruses Science (New York, N.Y.) [Online], 124(3212), pp. 119-120. https://doi.org/10.1126/science.124.3212.119.

[22] Glasgow, J., Everts, M. and Curiel, D. (2006) Transductional targeting of adenovirus vectors for gene therapy. Cancer gene therapy [online], 13(9), pp. 830-844. https://doi.org/10.1038/sj.cgt.7700928.

[23] Ginn, S.L., Alexander, I.E., Edelstein, M.L., Abedi, M.R. and Wixon, J. (2013) Gene therapy clinical trials worldwide to 2012-an update. The journal of gene medicine [online], 15(2), pp. 65-77. https://doi.org/10.1002/jgm.2698.

[24] Saha, B., Wong, C.M. and Parks, R.J. (2014) The Adenovirus genome contributes to the structural stability of the virion. Viruses [online], 6(9), pp. 3563-3583. https://doi.org/10.3390/v6093563.
[25] Monahan, P.E. and Samulski, R.J. (2000) Adeno-associated virus vectors for gene therapy: more pros than cons? Molecular medicine today [online], 6(11), pp. 433-440. https://doi.org/10.1016/S13574310(00)01810-4.

[26] Jooss, K. and Chirmule, N. (2003) Immunity to adenovirus and adeno-associated viral vectors: implications for gene therapy. Gene therapy [online], 10(11), pp. 955-963. https://doi.org/10.1038/sj.gt.3302037.

[27] Rabinowitz, J.E. and Samulski, R.J. (2000) Building a better vector: the manipulation of AAV virions. Virology [online], 278(2), pp. 301-308. https://doi.org/10.1006/viro.2000.0707.

[28] Kimura, B., Mohuczy, D., Tang, X. and Phillips, M.I. (2001) Attenuation of hypertension and heart hypertrophy by adenoassociated virus delivering angiotensinogen antisense. Hypertension [online], $37(2 \quad \mathrm{Pt} \quad 2), \quad$ pp. 376-380. https://doi.org/10.1161/01.HYP.37.2.376

[29] Wang, A.Y., Peng, P.D., Ehrhardt, A., Storm, T.A. and Kay, M.A. (2004) Comparison of adenoviral and adeno-associated viral vectors for pancreatic gene delivery in vivo. Human Gene Therapy [online], 15(4), pp. 405-413. https://doi.org/10.1089/104303404322959551.

[30] Anson, D.S. (2004) the use of retroviral vectors for gene therapywhat are the risks? A review of retroviral pathogenesis and its relevance to retroviral vector-mediated gene delivery. Genet Vaccines Ther [online], 2(9), pp. 1-13.

[31] Verma, I.M. and Weitzman, M.D. (2005) Gene therapy: twentyfirst century medicine. Annu.Rev.Biochem. [online], 74pp. 711-738. https://doi.org/10.1146/annurev.biochem.74.050304.091637.

[32] Kaplitt, M.G., Darakchiev, B. and During, M.J. (1998) Prospects for gene therapy in pediatric neurosurgery. Pediatric neurosurgery [online], 28(1), pp. 3-14. https://doi.org/10.1159/000028611.

[33] Shen, J., Huang, K.A., Chao-Yu, C., Chen, C., Lin, T. and Huang, Y. (2015) Seroprevalence of Herpes Simplex Virus Type 1 and 2 in Taiwan and Risk Factor Analysis, 2007. PloS one [online], 10(8), pp. e0134178. https://doi.org/10.1371/journal.pone.0134178.

[34] Latchman, D.S. (2001) Gene delivery and gene therapy with herpes simplex virus-based vectors. Gene [online], 264(1), pp. 1-9. https://doi.org/10.1016/S0378-1119(01)00322-5.

[35] Iizuka, S., Sakurai, F., Shimizu, K., Ohashi, K., Nakamura, S., Tachibana, M. and Mizuguchi, H. (2015) Evaluation of Transduction Properties of an Adenovirus Vector in Neonatal Mice. BioMed Research International [online], 2015. https://doi.org/10.1155/2015/685374.

[36] Thomas, M. and Klibanov, A. (2003) Non-viral gene therapy: polycation-mediated DNA delivery. Applied Microbiology and Biotechnology [online], 62(1), pp. 27-34. Park https://doi.org/10.1007/s00253-003-1321-8.

[37] Glover, D.J., Lipps, H.J. and Jans, D.A. (2005) towards safe, nonviral therapeutic gene expression in humans. Nature Reviews Genetics [online], 6(4), pp. 299-310. https://doi.org/10.1038/nrg1577.

[38] Ramamoorth, M. and Narvekar, A. (2015) Non-viral vectors in gene therapy- an overview. Journal of clinical and diagnostic research: JCDR [online], 9(1), pp. GE01-6. https://doi.org/10.7860/jcdr/2015/10443.5394.

[39] Cevher, E., Sezer, A.D. and Çağlar, E.Ş. (2012) Gene delivery systems: recent progress in viral and non-viral therapy. [online] INTECH Open Access Publisher.

[40] Smith, K.R. (2004) Gene Therapy: The Potential Applicability of Gene Transfer Technology to the Human Germline. International journal of medical sciences [online], 1(2), pp. 76-91. https://doi.org/10.7150/ijms.1.76.

[41] Kamimura, K., Suda, T., Zhang, G. and Liu, D. (2011) Advances in gene delivery systems. Pharmaceutical Medicine [online], 25(5), pp. 293-306. https://doi.org/10.1007/BF03256872.

[42] Issa, P.C. and MacLaren, R.E. (2012) Non-viral retinal gene therapy: a review. Clinical \& experimental ophthalmology [online], 40(1), pp. 39-47.

[43] Health and Research Authority (2015) Gene therapy Advisory Committee HRA URL http://www.hra.nhs.uk/resources/applying to-recs/gene-therapy-advisory-committee-gtac/. https://doi.org/10.1111/j.1442-9071.2011.02649.x. 